\title{
Metodología para la actualización de zonas de riesgo por inundación en el municipio de Florencia (Caquetá), mediante sobrevuelos de aeronaves remotamente tripuladas
}

\author{
Methodology to Update Flood Risk Areas in the \\ Municipality of Florencia (Caquetá) Through \\ Overflights of Remotely Piloted Aircraft
}

\author{
Roland Ricardo Arenas-Romero ${ }^{1}$, Sebastián Vidales-Claros², \\ Edwin Eduardo Millán-Rojas $3^{\natural}$ \\ ' Facultad de Ingeniería, Universidad de la Amazonia, Florencia, Colombia
${ }^{2}$ Facultad de Ingeniería, Universidad de la Amazonia, Florencia, Colombia
${ }^{3}$ Doctor en Ingeniería, Profesor de tiempo completo, Facultad de Ingeniería,
Universidad de la Amazonia, Florencia, Colombia
}

Correo electrónico: e.millan@udla.edu.co

Recibido: mayo 20 del $2018 \quad$ Aprobado: agosto 10 del $2018 \quad$ Disponible en línea: septiembre 1 del 2018

Cómo citar este artículo: R. R. Arenas-Romero, S. Vidales-Claros, E. E. Millán-Rojas, "Metodología para la actualización de zonas de riesgo por inundación en el municipio de Florencia (Caquetá), mediante sobrevuelos de aeronaves remotamente tripuladas", Revista Ingeniería Solidaria, vol. 14, no. 26, 2018. doi: https://doi.org/10.16925/in.v14i26.2454

\section{Resumen}

Introducción: este artículo es el resultado de un trabajo de investigación realizado como opción de grado en la modalidad de pasantía en el Instituto Geográfico Agustín Codazzi, seccional Caquetá, Colombia, durante el segundo semestre del 2017, apoyado por el programa de Ingeniería de sistemas de la Universidad de la Amazonia.

Objetivo: diseñar una metodología para la actualización de información catastral de zonas de riesgo utilizando una aeronave remotamente tripulada en el piedemonte amazónico colombiano para determinar el impacto generado por el fenómeno de las inundaciones.

Metodología: se emplearon dos métodos de investigación: el primero fue exploratorio, a partir del cual se establecieron las fuentes y referentes teóricos para el diseño de la metodología. El segundo fue proyectivo, con el cual se propuso un diseño metodológico para abordar la problemática de la actualización de las zonas de riesgo. El área de estudio comprendió un sector boscoso al borde de la quebrada La Perdiz en el municipio de Florencia.

Conclusiones: la metodología diseñada permitió determinar la existencia de 98 predios en zonas de riesgo por medio de una delimitación en el área de estudio, estableciendo la correcta funcionalidad de la inventiva propuesta.

Originalidad: el desarrollo de una metodología para la actualización catastral permite la integración de tecnología de hardware de forma fácil y la obtención de información detallada para la prevención de desastres naturales como las inundaciones.

Limitaciones: el proyecto solo abarca las áreas urbanas del piedemonte amazónico colombiano, dada la poca información existente del catastro rural en estas zonas del país.

Palabras clave: drones, inundación urbana, monitoreo, zonas de riesgo. 


\title{
Methodology to Update Flood Risk Areas in the Municipality of Florencia (Caquetá) Through Overflights of Remotely Piloted Aircraft
}

\begin{abstract}
Introduction: This article derives from the research conducted as a graduation option in the internship at the Agustín Codazzi Geographical Institute, Caquetá office, Colombia, during the second half of 2017, supported by the Systems Engineering program at the Universidad de la Amazonia.

Aim: To design a methodology to update cadastral information of risk areas using a remotely piloted aircraft in the Colombian Amazonian piedmont to determine the impact caused by the phenomenon of floods.

Materials and methods: Two research methods were used: the first one was exploratory, based on which the sources and theoretical references for the methodology design were established. The second one was forward-looking, with which a methodological design was proposed to address the problem of updating risk areas. The study area included a wooded sector on the edge of La Perdiz brook in the municipality of Florencia.

Conclusions: The methodology designed allowed to determine the existence of 98 properties in risk areas by means of delimitation in the study area, establishing the correct functionality of the proposed invention.

Originality: The development of a methodology for cadastral updating allows to integrate hardware technology easily and obtain detailed information to prevent natural disasters such as floods.

Limitations: The project only covers the urban areas of the Colombian Amazonian piedmont, given the little information available from the rural land register in these areas of the country.
\end{abstract}

Keywords: drones, urban flood, monitoring, risk areas.

\section{Metodologia para a atualização de zonas de risco por inundação no município de Florencia (Caquetá), mediante sobrevoos de aeronaves remotamente tripuladas}

\section{Resumo}

Introdução: este artigo é o resultado de um trabalho de pesquisa realizado como opção de graduação na modalidade de estágio, no Instituto Geográfico Agustín Codazzi, sede Caquetá, Colômbia, durante o segundo semestre de 2017, apoiado pelo programa de engenharia de sistemas da Universidad de la Amazonia.

Objetivo: desenhar uma metodologia para a atualização de informação cadastral de zonas de risco utilizando uma aeronave remotamente tripulada no sopé amazônico colombiano para determinar 0 impacto gerado pelo fenômeno das inundações.

Metodologia: foram utilizados dois métodos de pesquisa: o primeiro foi exploratório, a partir do qual foram estabelecidas as fontes e os referenciais teóricos para o desenho da metodologia. 0 segundo foi projetivo, com o qual foi proposto um desenho metodológico para abordar a problemática da atualização das zonas de risco. A área de estudo compreendeu um setor de florestas à beira da quebrada La Perdiz no município de Florencia.

Conclusões: a metodologia desenhada permitiu determinar a existência de 98 propriedades em zonas de riscos por meio de uma delimitação na área de estudo, estabelecendo a correta funcionalidade da proposta.

Originalidade: 0 desenvolvimento de uma metodologia para a atualização cadastral permite a integração de tecnologia de hardware de forma fácil e a obtenção de informação detalhada para a prevenção de desastres naturais como as inundações.

Limitações: o projeto somente abrange as áreas urbanas do sopé amazônico colombiano, dada a pouca informação existente do cadastro rural nessas regiões do país.

Palavras-chave: drones, inundação urbana, monitoramento, zonas de risco. 


\section{Introducción}

En el piedemonte amazónico colombiano se encuentra establecida la cabecera municipal del departamento del Caquetá. Este municipio, en su área urbana, se encuentra rodeado por múltiples afluentes hídricos. Su principal afluente, que atraviesa la ciudad de norte a sur, es la quebrada La Perdiz. Esta ha causado múltiples desastres naturales en época de lluvias, la cual dura casi 9 meses del año en esta región del país. Además, la quebrada es contaminada recurrentemente por los pobladores que habitan en su rivera, quienes además han contribuido a la deforestación y al daño de la calidad del agua en esta parte del municipio [1]. En este contexto, este artículo presenta los aspectos fundamentales para el desarrollo de una metodología para la actualización de información catastral de zonas de riesgo. La zona seleccionada para su estudio comprende 354 predios, los cuales están distribuidos en los barrios: El Raicero, Comuneros y La Estrella. Al implementar la metodología, se aplicó el decreto de prevención en riesgo, el cual plantea que las viviendas deben ubicarse a 30 metros de distancia con respecto al afluente. Esto arrojó un resultado de 98 viviendas en riesgo.

Los Sistemas de Información Geográfica (SIG) tienen la capacidad de capturar, analizar y procesar información espacialmente, lo que sirve para apoyar el trabajo de las organizaciones y brindar soluciones a problemas en el ámbito territorial, de gestión y de planificación.

En los últimos años, la tecnología ha evolucionado rápidamente debido a la necesidad de atender problemas de toda índole. Las aeronaves no tripuladas, o drones, son una herramienta que permite realizar tareas específicas en lugares de difícil acceso. Es por esto que su uso ha servido para atender problemas que afectan directamente a la población. Algunos de esos problemas son los derrumbes, las inundaciones, las avalanchas y otros eventos que son producidos, en ocasiones, por el uso indiscriminado del medio ambiente por parte de las personas. Esto tiene como resultado que la población sea la principal afectada por estas catástrofes, que generan pérdidas materiales y humanas.

En este panorama, las entidades gubernamentales tienen la obligación de contar con información actualizada que les permita identificar de manera adecuada y precisa las zonas de riesgo. En este sentido, es fundamental actualizar esta información permanentemente, debido a la impredecibilidad de las condiciones climáticas que termina afectando, directa e indirectamente, las condiciones de los terrenos.

Las metodologías se han entendido como el conjunto sistemático de estrategias, procedimientos, técnicas, pasos y tareas que se siguen para recolectar los datos y abordar su análisis, con miras a hallar una solución para este problema [2]. El catastro es un inventario público de datos sobre la propiedad de un país o distrito, que se ordenan metódicamente y se basa en el levantamiento de sus límites: tales propiedades están sistemáticamente rotuladas con identificadores únicos. Los linderos de la propiedad y el identificador de la parcela normalmente se muestran en mapas a gran escala [3].

El proceso de actualización cartográfica es extremadamente importante ya que, debido a las constantes alteraciones ocurridas en el espacio y al dinamismo con el que suceden, los mapas existentes no siempre coinciden con la realidad, es decir, la política de cartografía y de registro catastral no se ajustan al dinamismo con el que suceden dichas alteraciones [3].

\section{Revisión de la literatura}

El uso de aeronaves remotamente tripuladas es una práctica que se lleva a cabo en países desarrollados. Rabta, Wankmüller y Reine [4] hablan del uso de drones en la distribución de última milla en la logística humanitaria. También presentan un modelo de optimización para la entrega de múltiples paquetes de artículos de alivio ligero (por ejemplo, vacunas y tabletas de purificación de agua) por medio de drones a un cierto número de ubicaciones remotas dentro de un área propensa a desastres.

Otro aspecto estudiado es la logística en desastres. Esta da facilidades para atender situaciones posteriores a desastres. Para ello, se enfoca en el estudio y comparación de las situaciones presentes con aquellas previas al desastre, además de categorizar la mayoría de las investigaciones pasadas en 'optimización' y 'estudio conceptual', con base en el tipo de trabajos que se hayan realizado [5].

Soeta, Kabata y Kainuma [5] hablan, además, de las amenazas (accidentes) artificiales y de peligros naturales tales como inundaciones, tormentas, terremotos y erupciones volcánicas. Los 
procedimientos establecidos por las entidades nacionales para la prevención de desastres pueden fallar en situaciones de alivio de desastres, en las que se debe realizar un número anormal de operaciones de rescate. Es importante estudiar mecanismos capaces de dar más flexibilidad a estos procedimientos y estudiar la efectividad de los mismos en la fase de planificación.

\subsection{Aeronaves remotamente tripuladas (Dron)}

El artículo [6] muestra una revisión del uso de los drones en campos ambientales y agrícolas. Sin embargo, discute los costos de la tecnología, por lo que el estudio propone una plataforma para mejorar la precisión de la captura de imágenes y ayudar a la difusión de estas técnicas con bajo costo. En este punto, realizan una modificación de los dispositivos y algoritmos, lo que permite mejorar la geometría capturada por el dron en vuelo y recolectar un conjunto de datos más precisos.

La medición de inundaciones en lagos artificiales y su control están sujetos a trabajos no invasivos con el uso de drones que, combinados con un método de medición óptica de imágenes, pueden determinar los niveles de aumento y las posibles inundaciones rápidas. De esta manera, permiten que estas sean controladas desde la estación central. Una ventaja adicional de los drones es la capacidad de movilidad por todo el embalse y el envío de datos en tiempo real [7].

\subsection{Sistemas de información geográfica para el manejo ambiental}

Se han realizado algunos proyectos de sistemas de información aplicados al área ambiental en Colombia. Esto ha permitido conocer qué tanto se ha avanzado en el área de las tecnologías de georreferenciación. Es así como, por ejemplo, en el año 2014 se realizó un proyecto denominado "Uso de un sistema de información geográfica para el análisis de amenaza por inundaciones en la cuenca alta del Río Bogotá -Municipio de Cota- límites localidad de Suba" [8]. Este consistió en implementar un sistema de información geográfica basado en la recolección de información cartográfica, esencial para la toma de decisiones por parte de los organismos de control, con el fin de establecer acciones de mitigación y prevención en las zonas vulnerables. Con el sistema de información geográfica se pudo determinar que las áreas aferentes al Río Bogotá —en el municipio de Cota y sus límites con la localidad de Suba - tienen entre $50 \%$ y $60 \%$ de probabilidad de inundarse en épocas invernales, debido al desbordamiento de su afluente principal [8].

Otro proyecto, realizado por Alvarado Bello [9], generó una propuesta metodológica para la evaluación de la susceptibilidad yla socavación de puentes que se apoyaba en un Sistema de Información Geográfica (sIG). La propuesta consistió en crear una metodología para la priorización del riesgo ante la socavación en los puentes de Colombia, apoyados en el SIG ArcGIS v10 2. Este proyecto propuso una metodología de seis fases que, a su vez, estuvo dividida en una etapa preliminar de toma de decisiones, comprendida por las tres primeras fases, y una etapa complementaria, una cuarta fase, que implica la inspección en campo de los puentes. Al dividir la metodología en más fases, Alvarado se propuso discriminar de mejor forma las fases tradicionales utilizadas en las metodologías convencionales. En este caso, se optó por dividir la fase de investigación de oficina en tres etapas. Esto para darle mayor importancia a las diversas labores desarrolladas en esta fase preliminar, ya que al estar apoyados en un SIG se podía aprovechar y obtener mejores resultados del análisis. Cabe resaltar que la implementación del sig se refirió tanto a la organización e ingreso de información como a la asignación de atributos y características requeridas por la metodología para poder realizar los posteriores análisis y calificaciones. El aplicativo computacional alimenta y es retroalimentado por el sIG con lo cual fue posible llevar a cabo el proceso de priorización. Con el fin de validar la metodología, Alvarado realizó dos visitas de inspección visual en puentes localizados en la vía Bogotá-Villavicencio. Se generaron diversos mapas con ArcGIS, con lo que se logró demostrar su utilidad a la hora involucrar los conceptos de amenaza de riesgo y de vulnerabilidad. Con esto lograron obtener la priorización de los puentes y otros resultados satisfactorios, pues encontraron una correlación directa entre las calificaciones de las inspecciones del Sistema de Administración de Puentes de Colombia -SIPUCOL- y la metodología propuesta. 


\subsection{Sistemas de información geográfica para el manejo Territorial}

En el proyecto denominado "Análisis de la metodología de los Sistemas de Información Geográfica (sIG) en la cartografía de la guerra en Colombia" [10], los autores presentan la metodología que utilizan para la construcción de un atlas sobre el conflicto armado en Antioquia, enfocándose en el análisis de la construcción de mapas cuantitativos por medio de sIG. Además, destacan que la utilidad, los alcances y las limitaciones de las metodologías cartográficas al respecto es casi inexistente y evalúan tres aspectos que subyacen la creación de mapas sobre la guerra y que, por lo general, permanecen ocultos. Los

elementos analíticos que podrán ser útiles tanto para quien lea un mapa como para quien lo produzca: (i) las consecuencias a que dan lugar el uso de distintas bases cuantitativas, (ii) el papel que juegan las formas de clasificación estadística de los datos y (iii) las múltiples formas de representación cartográfica que los SIG ofrecen. Los mapas compendiados en el Atlas, tal y como se exponen en el artículo, permiten apreciar los múltiples resultados analíticos a que dan lugar la covariación de estos aspectos (fuentes, clasificaciones y representaciones) a la hora de construir y leer un mapa [10, p. 317].

En el artículo de investigación denominado "Aportes del análisis geográfico con Sistemas de Información Geográfica como herramienta teórica, metodológica y tecnológica para la práctica del ordenamiento territorial" [11], los autores presentan las relaciones entre la geografía como ciencia y el ordenamiento territorial como práctica, vinculados por el análisis geográfico mediante el uso de los sig. El alcance del análisis geográfico se define al interior del análisis espacial mediante los conceptos de: localización, distribución, asociación, interacción y evolución espacial, en la búsqueda de la realización de la síntesis del sistema territorial. Basándose en estas relaciones conceptuales, el artículo muestra las diferentes posibilidades ofrecidas por el análisis geográfico mediante el uso de los SIG en los diferentes componentes de la planificación y la gestión territorial.

\subsection{Trabajos realizados de forma regional}

En 2015 se realizó un estudio sobre la identificación de los elementos de la estructura ecológica, a escala local, para entes territoriales en Florencia, Caquetá [12]. Dicho proyecto se enfocó en: aportar al desarrollo ambiental territorial, reconocer los servicios ecosistémicos que estas áreas prestan y determinar los niveles de transformación de dichas zonas con la participación de la autoridad ambiental CorpoAmazonia, la alcaldía municipal de Florencia, el instituto de investigaciones amazónicas -SINCHI- y la Universidad de la Amazonia. Gracias a esto se identificaron las áreas de importancia ambiental, lo que dejó en evidencia la carencia de profesionales capacitados para desarrollar este ejercicio.

Por otra parte, el municipio de Florencia adelanta en 2018 la implementación del Sistema de Información Geográfica Web Fase III. Dicho proyecto tiene como base fundamental el desarrollo e implementación de la plataforma del sig en 2016 y 2017, para fortalecer la gestión de la Secretaria de Planeación y Ordenamiento Territorial, con los programas de licencias urbanísticas y estratificación; a la Secretaría de Ambiente y Desarrollo Rural, con los programas del PGAT, Créditos, coso y Parques y Zonas Verdes; y a la Secretaria de Vivienda, con el programa de subsidios de vivienda. El proceso de cartografía tiene previsto para los años siguientes (2018 y 2019): la actualización y generación de los mapas de los predios objeto de incentivo tributario; la identificación de las Unidades Productivas Agropecuarias -UPA- y su descripción productiva; la identificación de los productores y de los predios beneficiados con el crédito agropecuario; la identificación del coso, parques y zonas verdes, puntos críticos y zonas de minería en el municipio. Dicho proyecto tiene como finalidad facilitar el acceso, la consulta y el uso de información político administrativa, socioeconómica y ambiental georreferenciada para la planeación, el ordenamiento y la gestión territorial.

\section{Materiales y métodos}

Se planteó un diseño metodológico con las siguientes fases: 1) con la fase exploratoria se examinó a fondo el problema tratado y, se tomó como el factor 
más importante, la ubicación del área de estudio a intervenir mediante la identificación de variables internas como los cuerpos hídricos y las zonas urbanas. 2) La fase proyectiva realizó el análisis de los datos capturados gracias a las variables y la relación que existen entre ellas - con esto se abre la posibilidad de aplicar una normatividad que contribuya a determinar los sectores con amenaza de inundación-. Esta segunda fase buscó prever y anticipar situaciones futuras, lo que permitió generar un modelo de actualización. La conjunción de las fases - exploratoria y proyectiva- conllevó la evaluación de los procesos estipulados durante el proyecto para verificar el cumplimiento detallado de las etapas del diseño metodológico. De igual manera, fue fundamental que el desarrollo de las fases produciera como resultado información veraz. Por consiguiente, en esta fase se logró evidenciar las zonas urbanas que presentan riesgo de inundación. Esta metodología se planteó teniendo en cuenta la actualización de información de la cartografía catastral en las zonas de riesgo sobre los afluentes en el piedemonte amazónico colombiano del municipio de Florencia.

\subsection{Instrumentos/materiales}

El proceso de actualización cartográfica es extremadamente importante debido a las constantes alteraciones ocurridas en el espacio y al dinamismo con las que suceden. Los mapas existentes no siempre coinciden con la realidad, es decir, la política de cartografía y de registro catastral no se ajustan al dinamismo con las que suceden dichas alteraciones [1]. A continuación, se enuncian las herramientas y las zonas relevantes para la captura de información cartográfica que fueron relevantes para este trabajo.

\subsubsection{DroneDeploy}

Actualmente, los drones son la solución más rápida y sencilla para crear mapas aéreos y modelos 3D. En resumen, se dedican a dos cosas: por un lado se puede realizar la planificación del vuelo con su aplicación y, por otro, su software procesa las imágenes obtenidas creando el mapa o modelo deseado. Al unir estas dos tareas, se ahorra tiempo en procedimientos y procesamiento. El software y el procesamiento está en los servidores de la casa matriz del dispositivo, por lo que solo es necesario subir las imágenes conseguidas y, en breve, se obtienen los resultados. La compañía DroneDeploy se ha asociado con los principales fabricantes de drones, como DJI, para ofrecer el software a los usuarios en una variedad industrial, incluyendo la agricultura, minería, construcción, entre otras áreas [13].

\subsection{2. Área de estudio}

El 7 de abril del 2004 los habitantes de los barrios bajos de Florencia padecieron una inundación que afectó 65 familias y 261 personas. El 10 de junio del 2005 sucedió la última inundación torrencial reportada, en la que la quebrada La Perdiz creció súbitamente por las lluvias intensas presentadas en la parte alta de la microcuenca durante cinco horas. El saldo fue de 6600 personas damnificadas correspondientes a 1650 familias [14]. La población del barrio El Raicero, del municipio de Florencia, sufrió directamente el daño producido por la quebrada La Perdiz, como consecuencia de la elevación del nivel de las aguas.

El área de estudio comprende un sector boscoso al borde de la quebrada, infraestructura (casas) por lado y lado del afluente - lo que implica la inclusión de tres barrios: El Raicero, La Estrella y Los Comuneros-. También se analizaron los predios urbanos intervinientes en el estudio para la realización de la metodología. Es de resaltar que la información fue obtenida del Instituto Geográfico Agustín Codazzi (IGAC), sede Caquetá.

\subsubsection{Herramientas software}

Para llevar a cabo la implementación de las fases de la metodología y la actualización de información de las zonas de riesgo fueron necesarias las siguientes herramientas:

- Pix4D. La herramienta Pix4D sirve para generar el ortomosaico y modelo en 3D, también muestra la ruta realizada por el dron a la hora de capturar las imágenes. La herramienta, además, brinda el servicio online que permite descargar el modelo generado en varios formatos.

- ArcGis. ArcGis 10.3 es fundamental para generar la superficie obtenida a través de las ortofotos. Gracias a esto, se logran obtener las curvas de nivel del terreno y aplicar la normatividad con un buffer sobre el afluente. Por consiguiente, es posible realizar un análisis de los predios y 
zonas afectadas con esta herramienta. La licencia para este desarrollo fue aportada por el IGAC Caquetá.

- HEC-RAS. La simulación del afluente puede realizarse con la herramienta HEC-RAS 5.0. Es necesario, descargar el modelo en Pix4D en formato DSM para importarlo y así poder generar la simulación para determinar los puntos críticos del terreno en tiempos de una posible inundación.

- Sas Planet. Herramienta para extraer imágenes satelitales del terreno tratado. Las imágenes fueron utilizadas para generar una salida gráfica en ArcGis 10.3.

- Google Earth. Fue fundamental para la búsqueda del área de estudio. Cuando el terreno es extenso, se utiliza la herramienta para identificar el lugar y así ejecutar las fases de la metodología.

- DroneDeploy. La herramienta DroneDeploy es importante para indicarle al dron la ruta que debe realizar. Posteriormente se debe diseñar el recorrido y delimitar la zona de estudio.

A continuación, se mencionan las metas y actividades desarrolladas en el diseño metodológico específico.

Meta 1. Caracterización de variables internas y externas de la actualización catastral. Actividades relacionadas: a) ubicar el área de estudio a tratar; b) elegir una posible zona de riesgo de inundación con base en sus antecedentes; c) identificar variables internas: afluente, población, viviendas, vías; identificar variables externas: ortofotos, dron, herramientas software.

Meta 2. Informe de variables capturadas con factores de riesgo de inundación a partir de ortofotos generadas por el dron al realizar el recorrido diseñado en la zona estudio. Actividades relacionadas: a) analizar la importancia de las variables identificadas; b) estudiar el grado de incidencia que tienen estas variables dentro del sistema; c) establecer el recorrido que debe hacer el dron para la captura de imágenes - se utilizaron las herramientas de software para determinar la ruta a seguir, con el propósito de capturar las ortofotos del área de estudio-.

\section{Resultados}

Meta 1. Para el desarrollo de la caracterización de las variables internas y externas se utilizó el método de recolección de información que es la observación colectiva. Por medio de esta, se logró determinar los factores que sobresalían en el terreno. Para esto fue necesario observar el lugar de manera cuidadosa y destacar los aspectos principales para realizar el estudio.

La identificación de las variables se realizó para obtener el alcance del estudio con el objetivo de levantar datos puntuales. Por consiguiente, las variables fueron:

- Afluente. Los barrios El Raicero, Los Comuneros y La Estrella, del municipio de Florencia, han sufrido en los últimos años las fuertes crecientes de la quebrada. El nivel de la quebrada La Perdiz en el área de estudio presenta una cobertura de 407 metros. Esta parece poco amenazante para las personas, teniendo en cuenta la pérdida presentada por el afluente en algunas zonas del cauce.

- Viviendas. El área de estudio se delimitó de acuerdo con las viviendas afectadas por alguna creciente de la quebrada La Perdiz. Teniendo en cuenta los antecedentes, se estimó un total de 265 viviendas a lo largo y ancho del área estudiada. Actualmente la mayoría de las casas habitadas están construidas en concreto y una minoría en madera.

- Población. Los habitantes de los barrios El Raicero, Comuneros y La Estrella que se encuentran dentro del área de estudio se sienten amenazados por la quebrada La Perdiz. En la zona habitan más de 500 personas.

- Vías. Las vías de la zona de estudio se encuentran pavimentadas con un estado aceptable.

- Ortofotos. Las ortofotos se generaron a partir de la captura de imágenes del área de estudio en forma secuencial. Se obtuvo un total de 75 imágenes con dimensiones de 4000 x 3000 con una resolución horizontal y vertical de $72 \mathrm{ppp}$. Las ortofotos permitieron generar un modelo $3 \mathrm{D}$ con las herramientas mencionadas en la metodología y, de esta forma, se pudo estudiar el terreno de manera detallada.

- Dron. El dron Phantom 4, con una capacidad de sobrevuelo aproximadamente de 10 minutos, un peso de 1380 gr y una altura de 60 metros, realizó la captura de ortofotos. A partir de estas, se diseñó una ruta posterior al sobrevuelo, con el fin de obtener las ortofotos necesarias para el análisis del terreno. 


\subsection{Estructura de la metodología}

La combinación de métodos de investigación contribuye a ampliar las técnicas y modelos utilizados para construir la solución al problema de investigación planteado. En el presente proyecto se abordó una metodología mixta compuesta por los métodos exploratorio y proyectivo. El diseño metodológico se llevó a cabo de manera secuencial de cada una de sus fases, lo que se vio reflejado en los cumplimientos de las actividades anteriores. En la figura 1 se presenta la estructura básica de las fases de la metodología.

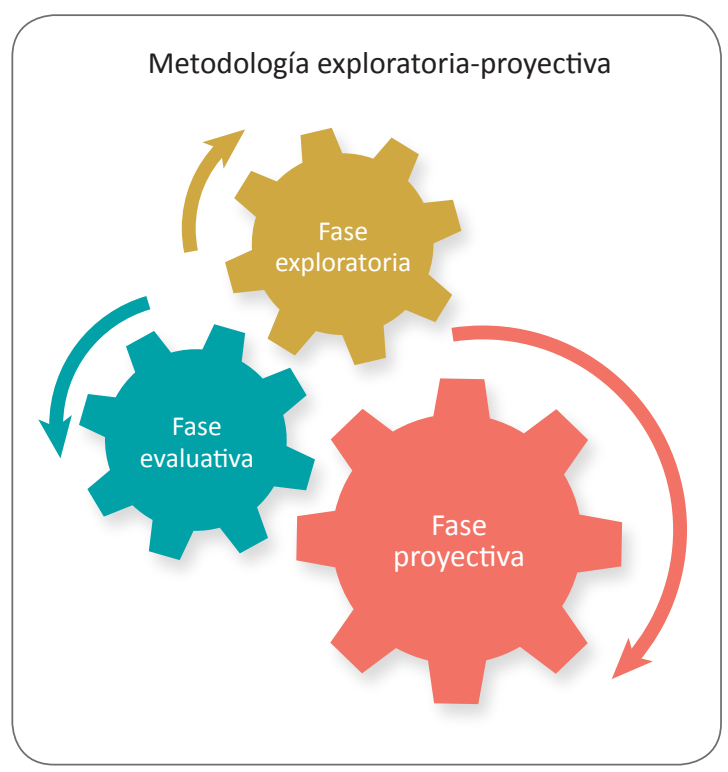

Figura 1. Diagrama de las fases exploratoria-proyectiva. Fuente: elaboración propia.

Al verificar el resultado detallado de cada una de las fases del diseño metodológico, se comprobó el cumplimiento de las metas y las actividades correspondientes a cada una de sus fases.

Según Abreu [15, p.191], la fase exploratoria se puede definir como "el objetivo de examinar o explorar un problema de investigación poco estudiado". Esta exploración se realizó a partir de fuentes de información primaria, secundaria y terciaria - en algunos casos mixtas o entrelazadas-, con el propósito de abordar todas las dimensiones del objeto investigado, ver figura 2.

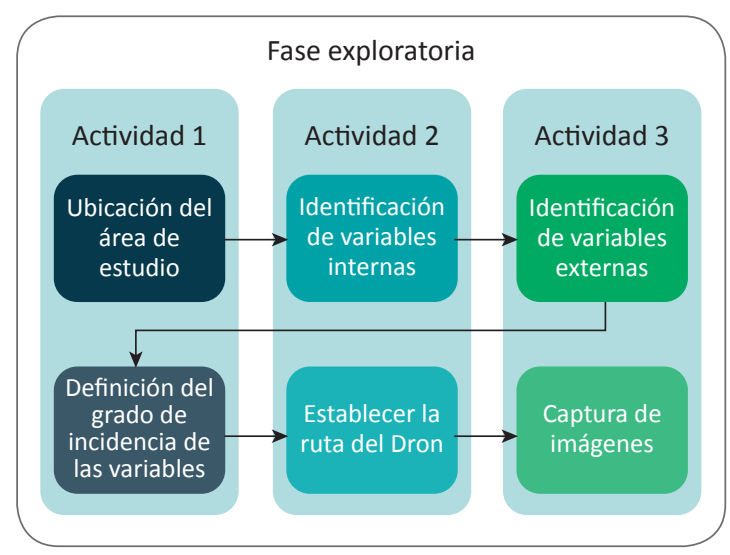

Figura 2. Diagrama de la fase exploratoria.

Fuente: elaboración propia.

De acuerdo con lo planteado por Córdoba y Monsalve [16, p. 3], la fase proyectiva "consiste en la elaboración de una propuesta o de un modelo, para solucionar problemas o necesidades de tipo práctico, ya sea de un grupo social, institución, una área en particular del conocimiento" (figura 3).

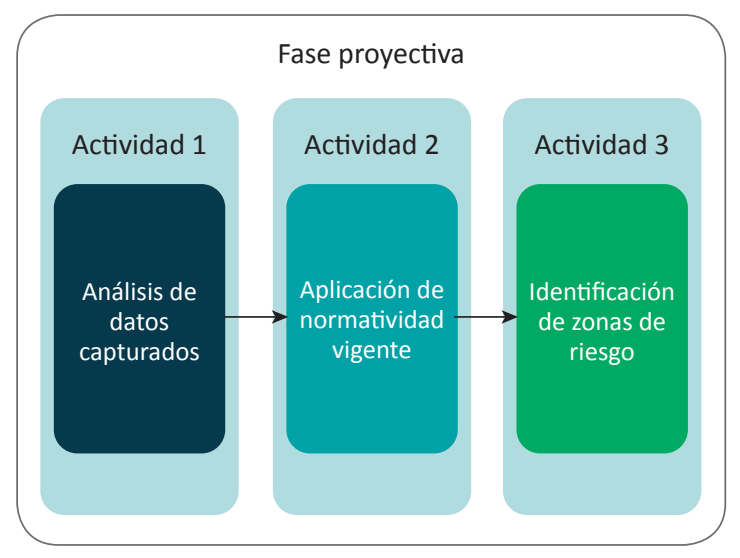

Figura 3. Diagrama de la fase proyectiva.

Fuente: elaboración propia.

La fase evaluativa (figura 4) consiste en corroborar el cumplimento detallado de la estructura de la metodología. En esta se verificó a cabalidad el desarrollo de cada una de las etapas del diseño y se corroboró el resultado de las metas propuestas, que se vieron reflejadas al culminar las actividades. 


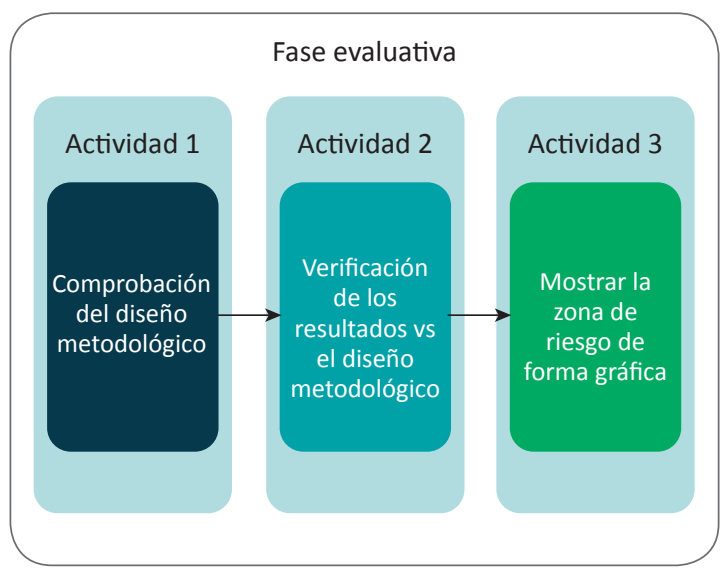

Figura 4. Diagrama de la fase evaluativa. Fuente: elaboración propia.

\subsection{Ruta del recorrido hecho por el dron}

Con el uso de DroneDeploy, se logró establecer el plan de vuelo necesario para la captura de imágenes por parte del dron en el área de estudio tratada. La interfaz del software permitió configurar las variables requeridas: el área de acción para realizar el sobrevuelo, la cantidad de puntos o estaciones en las cuales el dron tomó cada fotografía y la elevación del recorrido. Estas variables dependen exclusivamente de las condiciones específicas de la zona en la cual se encuentra el estudio de caso seleccionado.
La figura 5 muestra el plan de vuelo obtenido con la ayuda de la herramienta. Las líneas blancas simbolizan las vías y cada punto rojo simboliza una estación en la cual el dron tomó una fotografía. Como resultado, al final del recorrido se obtuvieron las imágenes necesarias para realizar el análisis requerido.

\subsection{Captura de imágenes en el área de estudio seleccionado}

La captura de imágenes se realizó mediante un trabajo de campo en el área de estudio, con lo ejecutado del plan de vuelo previamente. Fue importante tener presentes las condiciones climáticas, ya que, para el éxito de la operación no se debían presentar lluvias al momento de la realización del vuelo. Además, fue necesario mantener la estabilidad en el aire y verificar las condiciones de iluminación para obtener un resultado óptimo, que diera la posibilidad de un análisis adecuado.

Se usó el dron Phantom 4. Es importante aclarar que el dron utilizado para la captura de las imágenes en este tipo de procesos debe ser igual o superior a las características mencionadas en el apartado de materiales y métodos, debido a la calidad requerida en las imágenes. La figura 6 ilustra los puntos azules y verdes, de las 75 capturas obtenidas por el dron, y muestra la cobertura de cada área del recorrido programado, lo que, en consecuencia, permitió generar un ortomosaico.

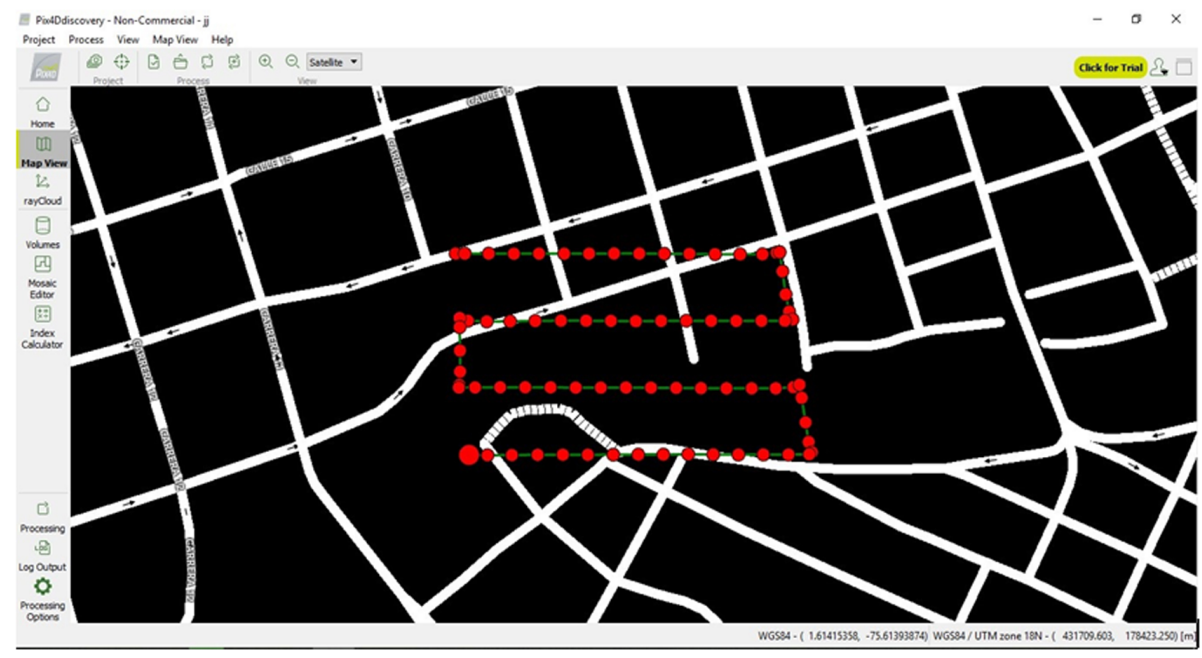

Figura 5. Vista del mapa de recorrido realizado por el dron con la herramienta Pix4D.

Fuente: elaboración propia. 


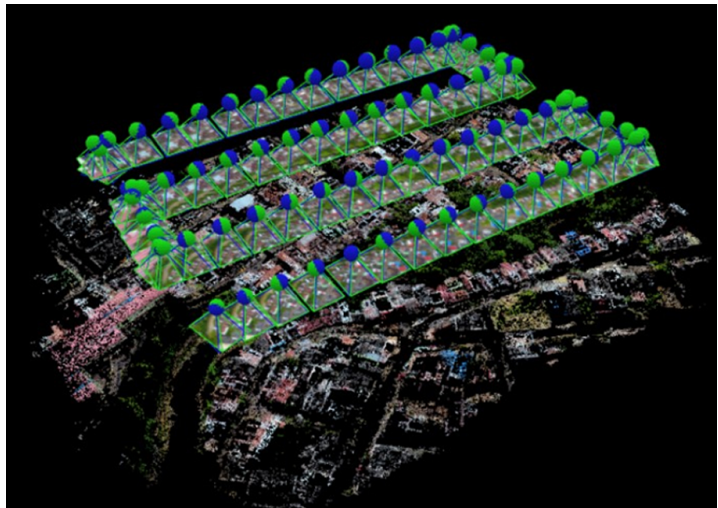

Figura 6. Imágenes miniatura del recorrido realizado por el drone Phantom 4.

Fuente: elaboración propia.

\subsection{Puntos críticos y zonas de riesgo de inundación}

En el transcurso de las fases de la metodología y partiendo de la base de información obtenida por el dron y analizada previamente, se logró determinar los puntos críticos de la zona de estudio.

\subsubsection{Analizar los datos capturados en ortofotos por el dron}

Después de realizar la observación de cada una de las ortofotos obtenidas previamente y establecer el análisis para valorar la ubicación de los puntos definidos en el plan de vuelo, se realizó el análisis correspondiente al terreno del área de estudio, lo que dio como resultado la generación de las curvas de nivel. Luego de tener estas, se procedió a realizar el análisis mediante la herramienta Pix4D, en la que se construyó el modelo en $3 \mathrm{D}$, el cual permitió apreciar las características del terreno, las variables asociadas y definidas previamente: vías, casas, árboles y el cauce de la quebrada. La figura 7 muestra las fotografías aéreas realizadas desde el software Pix4D, en las que se observan detalladamente todos los elementos del área de estudio.

\subsection{Aplicar la normatividad para establecer las zonas de riesgo}

La normatividad vigente aplicable a las fuentes hídricas en Colombia se encuentra estipulada en el Decreto 2811 de 1974, artículo 83, el cual establece que "las zonas que se encuentren hasta un máximo 30 metros de distancia a fuentes hídricas se declaran zonas en estado de alto riesgo". Por consiguiente, al aplicar esta norma se logró determinar que un conjunto de viviendas no cumplían con lo establecido en el decreto. Para identificar cuáles eran las zonas en esa condición se utilizó la herramienta ArcGis 10.3 para el análisis del terreno a partir de un shapefile proporcionado por el IGAC, el cual contiene todos los predios registrados ante esta entidad y se realiza una intercepción con el área de estudio tratada.

En la figura 8 se muestra el shapefile llamado "Viviendas", correspondiente a los predios urbanos. Luego se procedió con la realización de un buffer con un área de acción de 30 metros para determinar la zona de protección que la población debía respetar.
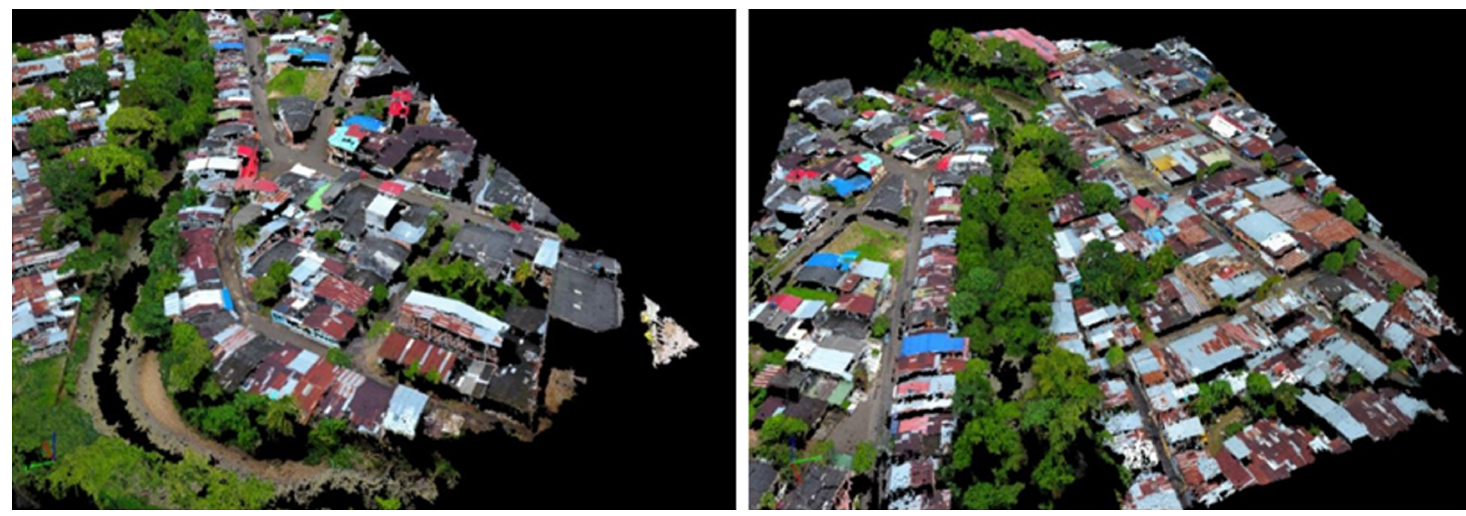

Figura 7. Modelo 3D en el software Pix4D (izq), Vista general del modelo 3D (der).

Fuente: elaboración propia. 


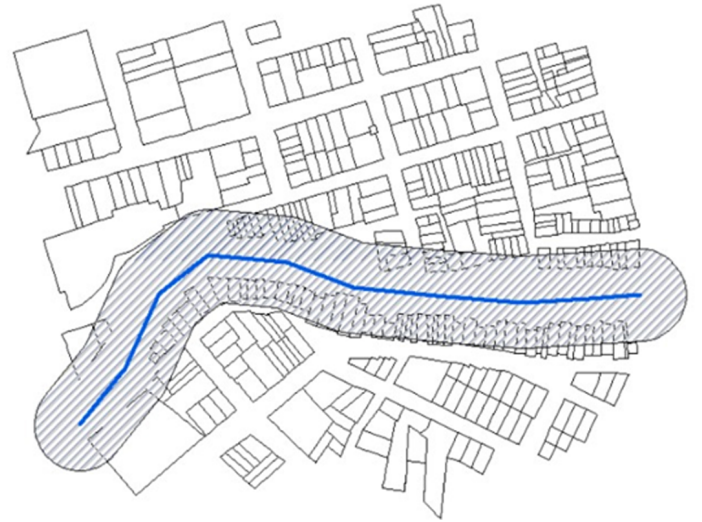

Figura 8. Buffer generado por ArcGis 10.3 para identificar la zona de riesgo.

Fuente: elaboración propia.

\subsection{Puntos críticos vulnerables a posibles inundaciones}

Mediante el Modelo Digital del Terreno (DTM) obtenido con la herramienta Pix4D (simulación 3D), se logró identificar las características geográficas de la superficie reflejadas en la elevación, dada en metros sobre el nivel del mar, de cada parte del área de estudio seleccionada $\mathrm{y}$, con ello, se determinaron los puntos críticos de inundación. El anterior criterio se estableció con base en una simulación realizada con la herramienta HEC-RAS, que agrupa de manera organizada las superficies de acuerdo con la altura presente en la misma. Esto permitió determinar cuáles eran los puntos bajos y, por lo tanto, críticos al momento de una inundación. La figura 9 muestra una toma aérea de los puntos críticos y los ilustra como círculos azules.

La imagen se cargó en la herramienta HECRAs, la cual permitió obtener la escala de colores del terreno en metros sobre el nivel del mar. Las zonas de riesgo fueron identificadas a partir del mínimo valor en la escala, por lo que se pudo mostrar cuáles serían los principales afectados en una posible creciente de la quebrada.

\subsection{Zonas de riesgo por inundación del área de estudio, a partir de la aplicación del diseño metodológico}

Para la comprensión de la información obtenida, y teniendo en cuenta el proceso para el tratamiento de datos realizado, fue necesario evidenciar las

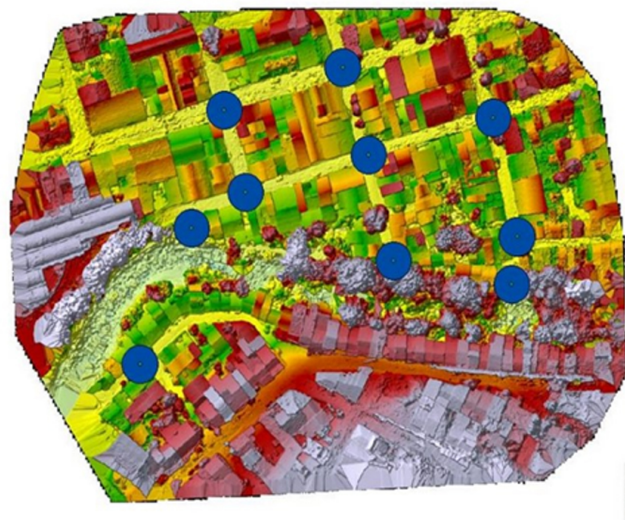

Figura 9. Puntos de alto riesgo sobre la imagen de superficie obtenida por Pix4D online.

Fuente: elaboración propia.

zonas de riesgo de manera gráfica para tener una visión general de la magnitud del riesgo latente en una zona geográficamente pequeña que está densamente habitada.

Con ayuda de la herramienta HEC-RAs se obtiene una simulación de una posible inundación realizada en el área de estudio. Con esta, se determinó gráficamente el área afectada y dio como resultado las zonas de alto riesgo, reflejadas en la figura 10, que muestra las zonas en estado de protección de acuerdo con la normativa vigente en Colombia.

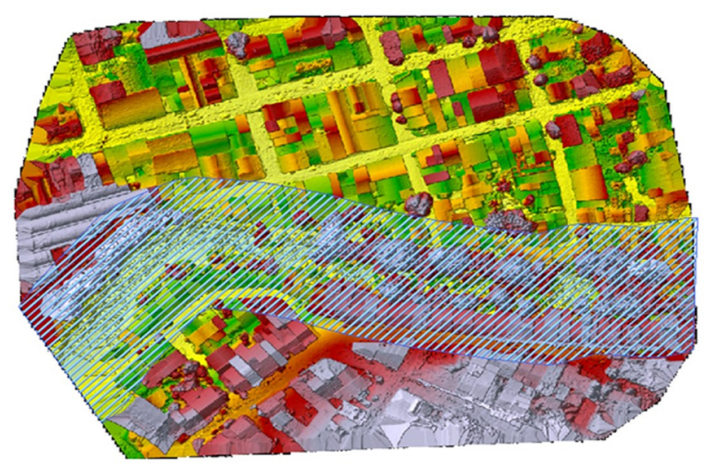

Figura 10. Imagen en formato .tif junto al buffer de 30 metros. Fuente: elaboración propia.

La imagen muestra la simulación obtenida con la herramienta HEC-RAs en la cual se aprecia cómo afectaría una posible inundación al área de 
estudio. Los puntos más afectados son los determinados como críticos debido a su baja altura. El procedimiento para detectar la zona vulnerable a problemas de inundación se realizó por medio de una imagen generada a partir de la manipulación de las ortofotos con la herramienta Pix4D.

$\mathrm{Al}$ introducir los datos requeridos por el software, se apreció la magnitud del posible desbordamiento de la quebrada La Perdiz y el impacto negativo que tendría este evento natural. De tal manera, se realizó la simulación con datos cercanos a la realidad para observar el comportamiento del afluente en caso de una emergencia. Del mismo modo, fue indispensable delimitar la zona para reconocer las viviendas en riesgo latente de sufrir daños materiales o pérdidas humanas. De esta forma, se determinó la cantidad y la ubicación de los predios en riesgo (figura 11).

Se realizó un censo en los barrios El Raicero, Los Comuneros bajos y La Estrella. Se hizo un trabajo de campo por los lugares aledaños a la quebrada para identificar la cantidad de viviendas, talleres o locales de trabajo y personas afectadas dentro del área delimitada por los 30 metros de protección establecidos por el decreto 2811 de 1974. Gracias a ello, se encontraron 60 casas habitadas por 194 personas. Del mismo modo, se identificaron 26 establecimientos o talleres en el sector de estudio, con un total de 58 personas, para un total de 86 predios y 252 personas afectadas.

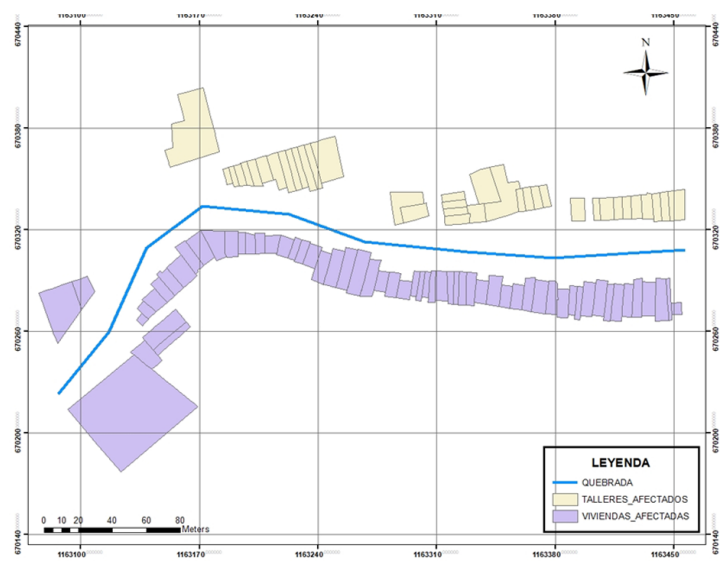

Figura 11. Predios urbanos afectados dentro del rango de los 30 metros. Barrios El Raicero y Los Comuneros.

Fuente: elaboración propia.
Del mismo modo, se analizó detalladamente el procedimiento y se desarrolló a cabalidad cada una de sus etapas, lo que permitió mostrar que es posible aplicar la metodología en cualquier contexto gracias al diseño establecido, que facilita su ejecución en cualquier ámbito y permite la generación de los datos necesarios para identificar un posible riesgo, tanto para estructuras como para vidas humanas.

\section{Discusión}

En la actualidad, las comunidades se ven enfrentadas a fenómenos naturales generadores de incontables tragedias humanas. Sin embargo, el ser humano es el causante, en su mayoría, de dichas tragedias. Los daños materiales y a las personas son ocasionados por el incumplimiento de las normas establecidas para la protección de la vida. Este estudio evidencia claramente la ubicación de asentamientos en zonas de alto riesgo en el municipio de Florencia. Sin embargo, deja abierta la discusión del papel de los entes reguladores de la planificación urbana.

Los desarrollos regionales para la prevención del riesgo por inundaciones se han quedado en los libros y documentos, lo que favorece la ocurrencia de tragedias recurrentemente. Es importante considerar la necesidad de llevar la teoría a la práctica y este proyecto lo logra, al mostrar las zonas de riesgo y la necesidad de tomar decisiones de índole administrativa para la prevención de pérdida de vidas humanas.

La metodología desarrollada aporta a la generación de conocimiento, a partir de la experiencia obtenida en el terreno y gracias a los estudios realizados en la definición de zonas de riesgo. Además contribuye a la consecución de información en tiempo real para determinar las consecuencias de las decisiones de los pobladores asentados en las orillas de los afluentes hídricos.

La tecnología facilita la obtención de información en tiempo real y hace ver los errores de índole social en el daño ambiental ocasionado por las comunidades a lo largo de los afluentes hídricos. El uso de drones cada día se abre paso para avanzar en la consolidación de información en los diferentes ámbitos de la sociedad moderna. Con desarrollos como estos [6], se busca optimizar los recursos 
y generar mayor autonomía de los drones, con el propósito de ponerlos al alcance de toda la sociedad y a un costo cada vez menor.

\section{Conclusiones}

El municipio de Florencia, en el Caquetá, se caracteriza por sus ricos yacimientos de agua en la cordillera oriental de los Andes. La quebrada La Perdiz atraviesa a lo largo y ancho este municipio y genera constantes alertas a sus habitantes. Esto se debe a las fuertes lluvias presentadas durante el $80 \%$ del año y al grado de deforestación y de contaminación causada por la población asentada alrededor de este afluente. Esto tiene como consecuencia el aumento del caudal de manera impredecible, lo que pone en riesgo la integridad de las personas y los objetos materiales de quienes colindan con la fuente hídrica.

Este proyecto identificó las variables asociadas al problema de investigación y estableció el marco referencial para el diseño metodológico de la actualización de zonas de riesgo por inundación en el municipio de Florencia, mediante sobrevuelos de drones. Con esto, se generó una metodología por fases y se definieron claramente los instrumentos necesarios para el análisis y el procesamiento de la información recolectada.

La captura de imágenes para el análisis de las variables dentro del sistema se hizo con la herramienta tecnológica Phantom 4. El comportamiento de las variables se determinó en función de la simulación del afluente, que involucró variables internas y externas, y la descripción de las características principales y su importancia dentro de la zona a tratar.

Se establecieron datos concretos que permitieron determinar la existencia de 98 predios en zonas de riesgo por medio de una delimitación del área de estudio con la ayuda de una herramienta de software, mediante la aplicación del artículo 83 del decreto 2811 de 1974. Los habitantes fueron censados con el fin de conocer la totalidad de personas en riesgo y se logró establecer que el área de estudio elegida contiene un alto grado de vulnerabilidad para la mayor parte de las viviendas y de la población colindante al afluente.

La sinergia de las fases es el resultado de la metodología propuesta, lo que comprueba el cumplimiento de las etapas por medio del diseño metodológico para la actualización de zonas de riesgo con un tratamiento de datos confiables. Esto fortalece le manejo de información y facilita el cumplimiento de los objetivos del sistema.

El proyecto se desarrolló en función del objetivo general, que corresponde a la implementación del diseño metodológico para la actualización de información catastral de zonas de riesgo con el uso de un dron en el piedemonte amazónico, a través de una secuencia de fases que permitieron identificar el impacto de las inundaciones en el área de estudio.

\section{Agradecimientos}

A la seccional Caquetá del Instituto Geográfico Agustín Codazzi (IGAC), a la Universidad de la Amazonia y el programa de Ingeniería de Sistemas de la Facultad de Ingeniería.

\section{Referencias}

[1] L. M. Losada y M. P. Rodríguez, "Evaluación de la calidad del agua de la quebrada La perdiz en el área urbana de Florencia (Caquetá, Colombia)", Momentos de Ciencia, vol. 7, no. 2, pp. 118-126, 2015. Disponible en: https://goo.gl/iytRoK

[2] V. M. Niño Rojas, Metodología de la Investigación, Bogotá: Ediciones de la U, 2011, pp. 15-158. Disponible en: https://goo.gl/tUfsuW

[3] A. Amorim y G. Souza, "Actualización catastral en cortos períodos de tiempo: Un problema minimizado por la evolución tecnológica", en $6^{a}$ Semana Geomática, Bogotá, 2005, pp. 1-11. Disponible en: https://goo.gl/kHWiqm

[4] B. Rabta, C. Wankmüller y G. Reiner, "A Drone Fleet Model for Last-Mile Distribution In Disaster Relief Operations", International Journal of Disaster Risk Reduction, vol. 28, no. 2, pp. 107-112, 2018. doi: https://doi.org/10.1016/j.ijdrr.2018.02.020

[5] H. Soeta, M. Kabata y Y. Kainuma, "Development Of A Logistics Model For Disaster Relief Operations", Journal of Japan Industrial Management Association, vol. 66, no. 1, pp. 23-29, 2015. doi: https://doi. org/10.11221/jima.66.23

[6] R. A. Oliveira, E. Khoramshahi, J. Suomalainen, T. Hakala, N. Viljanen y E. Honkavaara, "Real-Time And Post-Processed Georeferencing For Hyperpspectral Drone Remote Sensing", Remote Sensing and Spatial Information Sciences, vol. 42, no. 2, pp. 789795, 2018. doi: https://doi.org/10.5194/isprs-archives-XLII-2-789-2018 
[7] E. Ridolfi y P. Manciola, "Water Level Measurements from Drones: A Pilot Case Study at a Dam Site", Water, vol. 10, no. 3, pp. 1-10, 2018. doi: https:// doi:10.3390/w10030297

[8] S. A. Alvarado Bello, Uso de un sistema de información geográfica para el análisis de amenaza por inundaciones en la cuenca alta del Río Bogotá Municipio de Cota limites localidad de Suba. Bogotá: U. Católica, pp. 1-7, 2015. [Trabajo de grado]. Disponible en: https://goo.gl/qA8nXx.

[9] G. Giraldo Arenas y D. E. Vega Castillo, Propuesta metodológica para la evaluación de la susceptibilidad y socavación de puentes apoyada en un Sistema de Información Geográfico (SIG), Bogotá, Universidad Javeriana, 2013. [Trabajo de grado]. Disponible en: http://hdl.handle.net/10554/11124

[10] N. Espinosa, J. Monsalve y S. Gómez, "Análisis de la metodología de los Sistemas de Información Geográfica (SIG) en la cartografía de la guerra en Colombia”, Tabula Rasa, vol. 19, no. 1, pp. 316353, 2013. Disponible en: http://www.redalyc.org/ html/396/39630036015/

[11] G. D. Buzai, Aportes del análisis geográfico con Sistemas de Información Geográfica como herramienta teórica, metodológica y tecnológica para la práctica del ordenamiento territorial, Argentina, Universidad Alberto Hurtado, pp. 113-138, 2013. [En línea]. Disponible en: http://repositorio.uahurtado.cl/handle/11242/3529
[12] H. A. Tovar Segura, Aproximación a la identificación de los elementos de la estructura ecológica a escala local para entes territoriales en el municipio de Florencia (Caquetá), Manizales, Universidad de Manizales, pp. 1-39, 2015. [En línea]. Disponible en: http://ridum.umanizales.edu.co:8080/xmlui/handle/6789/2741

[13] P. Rojas y J. Duvan, Drones en las Geociencias. Guía de Implementación en la Cartografía, Fusagasugá, Universidad de Cundinamarca, pp. 73-109, 2017. [Tesis de doctorado]. Disponible en: http://repositorio.ucundinamarca.edu.co:8080/xmlui/handle/123456789/550

[14] I. C. Torres Perafán y M. A. Castro Ramón, Estudio de cambios de coberturas y usos del suelo en la cuenca del Rio Hacha, Florencia-Caquetá, Manizales, Universidad de Manizales, pp. 5-63, 2016. [En línea]. Disponible en: http://ridum.umanizales.edu. co:8080/xmlui/handle/6789/2703

[15] J. L. Abreu, "Hypothesis, Method \& Research Design", Daena: International Journal of Good Conscience, vol. 7, no. 2, pp. 187-197, 2012. [En línea]. Disponible en: http://www.spentamexico.org/v7n2/7(2)187-197.pdf

[16] M. Córdoba y C. Monsalve, Tipos de investigación: predictiva, proyectiva, interactiva, confirmatoria $y$ evaluativa, Venezuela: Fundación Sypal, Caracas, pp. 3-5, 2011. Disponible en: http://www.scribd. com/doc/2561176/Algunostipos-de-investigacion-abordaje-holístico. 